\title{
High-temperature corrosion performance of austenitic stainless steels type AISI 316L and AISI 321H, in molten Solar Salt
}

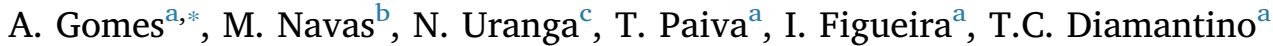 \\ ${ }^{a}$ Laboratório Nacional de Energia e Geologia, I.P. (LNEG), Estrada do Paço do Lumiar, 22, 1649-038 Lisboa, Portugal \\ ${ }^{\mathrm{b}}$ Centro de Investigaciones Energéticas Medioambientales y Tecnológicas (CIEMAT), Avenida Complutense 40, Madrid 28040, Spain \\ ${ }^{\mathrm{c}}$ IK4-TEKNIKER Research Center, 20600 Eibar, Spain
}

\section{A R T I C L E I N F O}

\section{Keywords:}

Thermal energy storage

High temperature corrosion

Austenitic stainless steels

Molten nitrate salt

\begin{abstract}
A B S T R A C T
The corrosion rates of AISI $316 \mathrm{~L}$ and AISI $321 \mathrm{H}$ austenitic stainless steel, immersed in a stagnant isothermal mixture of $60 \% \mathrm{NaNO}_{3}$ and $40 \% \mathrm{KNO}_{3}$ molten salt at $550{ }^{\circ} \mathrm{C}$ in atmospheric air are 8.6 and $9.0 \mu \mathrm{m} / \mathrm{yr}$, respectively. The corrosion mechanism was proposed by recording the weight changes of the steel coupons at different time intervals up to $3000 \mathrm{~h}$, and by the characterization of multilayer oxide scales formed on the steel surface. Multilayers made of different oxides, mainly $\mathrm{Fe}_{2} \mathrm{O}_{3}$ and $\mathrm{Fe}_{3} \mathrm{O}_{4}$, are the principal scale products. At $3000 \mathrm{~h}$, the thickness of the scale layer formed on AISI $321 \mathrm{H}(7.5 \pm 2.9 \mu \mathrm{m})$ is slightly higher than the one formed at the AISI 316L $(6.9 \pm 2.1 \mu \mathrm{m})$. This small difference might reflect the partial spallation of the corrosion layer on AISI $321 \mathrm{H}$, which is seen for times longer than $1000 \mathrm{~h}$. A minimal change of the composition of the molten nitrate salt is observed in time and is predominantly due to the appearance of soluble chromate products and nitrite compounds ( $0.004 \mathrm{wt} \%$ and $1.4 \mathrm{wt} \%$ at $3000 \mathrm{~h}$, respectively). The observed corrosion behaviour of these alloys shows that they are good candidate for usage as containers of molten nitrate salts in the thermal energy storage (TES) system for a CSP plant.
\end{abstract}

\section{Introduction}

Thermal energy storage (TES) is a key performance indicator (KPI) that helps understanding how to improve the viability and dispatchability of CSP plants. The accomplishment of TES KPI targets will optimize the solar heat storage from solar radiation, to generate electricity at night or on cloudy days with significant economic advantages to the solar plants (Kearney et al., 2003; Kuravi et al., 2013; Liu et al., 2016).

Sensible heat storage materials as nitrate molten salts (MS) have been extensively used in parabolic trough power plants, to transfer and store heat given their unique thermal properties (Kearney et al., 2004; Vignarooban et al., 2015; Weinstein et al., 2015). In central tower technology, based on MS as storage solution and as heat transfer fluid (HTF), the cold tank operates at $290^{\circ} \mathrm{C}$ and the hot tank at temperatures greater than $550{ }^{\circ} \mathrm{C}$ (Liu et al., 2016). Due to the high operating temperature, the construction of the hot storage containment components requires the usage of stainless steel (SS) materials, being the austenitic stainless steels the prime candidates (Dorcheh et al., 2016; Walczak et al., 2018).

Currently, the Solar Salt - the binary mixture of sodium nitrate and potassium nitrate (60-40 wt\%) - is widely used as HTF and storage material. It has a superior thermal stability and low cost when compared with other inorganic salt options (Bradshaw et al., 2009).

At high temperatures, evidence exists that nitrate ions decompose into nitrite ions and oxygen (Nissen and Meeker, 1983). These strong oxidizing species combined with operating temperatures plus salt impurities generate favourable conditions to increase corrosion susceptibility of stainless steels (Speidel et al., 1999). In this context, it is crucial to evaluate the corrosion resistance and lifetime of stainless steels to optimize the material selection since their failure could lead to severe damage and cost increase of the CSP plants operation.

Previously published works demonstrated the compatibility of Solar Salt with common austenitic stainless steels like 304, 316 and 347 as shown by their low descaled loss values (Attia et al., 1999; Kruizenga and Gill 2014; Liu et al., 2016).

In the present work, a comparative study of the corrosion resistance of two austenitic stainless steels - low-carbon 316 stainless steel (AISI 316L) and titanium stabilized 321 stainless steel (AISI 321H) - was performed, with the purpose of evaluating the impact of high temperature MS contact on the aging, stability and corrosion of container and piping materials generally used in CSP. To achieve this, static immersion tests with large volume of Solar Salt have been performed,

\footnotetext{
* Corresponding author.

E-mail address: anabela.boavida@lneg.pt (A. Gomes).
} 